\title{
Letramento Visual na Educação Infantil: uma Proposta de Ensino
}

\author{
Visual Lettering in Child Education: a Teaching Proposal
}

\author{
Ana Carolina Vieira de Brito ; Alda Maria Coimbra Aguilar Maciel \\ aPrefeitura da Cidade de Rio de Janeiro. RJ, Brasil. \\ 'Instituto Federal de Educação, Ciência e Tecnologia do Rio de Janeiro, Programa de Pós-Graduação Stricto Sensu em Práticas de Educação Básica. \\ RJ, Brasil. \\ *E-mail: coimbra.aldamaria@gmail.com \\ Recebido em: 21/02/19; Aceito em: 03/07/19
}

\begin{abstract}
Resumo
O artigo discute o letramento na Educação Infantil por meio da pedagogia de multiletramentos. Foi realizada uma retrospectiva histórica e breve análise dos documentos Referencial Curricular Nacional da Educação Infantil - RCNEI, Diretrizes Curriculares Nacionais para a Educação Infantil - DCNEI e Orientações Curriculares para a Educação Infantil - OCEI. Para a elaboração do produto educacional, foram utilizados os conceitos da Gramática do Design Visual - GDV e a estrutura narrativa de Labov para a organização da contação de histórias. Baseou-se nas concepções do método pesquisa-ação de cunho qualitativo, cujo campo de aplicação foi uma creche pública do Município do Rio de Janeiro - segmento Maternal I -, localizada em uma comunidade da zona Norte do Estado do Rio de Janeiro. Iniciou-se a elaboração do produto utilizando a opinião das professoras da unidade, na qual a pesquisa foi realizada, para que o material fizesse realmente sentido para elas. Ao disponibilizar o produto, esperou-se perceber cada teoria sendo utilizada em favor da formação de sujeitos mais autônomos, críticos e criativos.
\end{abstract}

Palavras-chave: Multiletramento. Multimodalidade. Educação Infantil. Caderno Pedagógico.

\begin{abstract}
This article presents a research that discusses a literacy instrument in Early Childhood Education through multiliteracy pedagogy. It was started with a historical retrospective and a brief analysis was carried out of the National Curricular Reference Framework for Early Childhood Education (RCNEI), the National Curriculum Guidelines for Early Childhood Education (DCNEI) and the Curriculum Guidelines for Early Childhood Education (OCEI). For the elaboration of the educational product, in turn, the concepts of the Grammar of Visual Design (GDV) and the narrative structure proposed by Labov for the organization of storytelling were used. It was based on the conceptions of the qualitative action research methodology, whose field of application was a public nursery school of the Municipality of Rio de Janeiro - Maternal I -, located in a community in the northern area of the State of Rio de Janeiro. The elaboration of the product was started using the teacher' opinion of the unit where the research was carried out so that the material could make real sense to them. In making our product available, it is hoped to perceive each theory being used in favor of the formation of more autonomous, critical and creative subjects.
\end{abstract}

Keywords: Multiliteracy. Multimodality. Child Education. Early Childhood Education. Pedagogical Handbook.

\section{Introdução}

O presente artigo apresenta a pesquisa: "Imagens que contam: a pedagogia dos multiletramentos na Educação Infantil", que tem como objetivo discutir o multiletramento na Educação Infantil, por meio de práticas de letramento visual com gêneros multimodais. A partir do estudo dessas teorias foi desenvolvido um caderno pedagógico, que orienta o profissional da Educação Infantil para o trabalho com o letramento visual com atividades multimodais, que envolvem os diversos aspectos do texto, principalmente, a imagem.

O texto multimodal é aquele que relaciona cor, imagem, links, som e demais aspectos que a sociedade atual demanda. Santos (2008) sinaliza a importância do uso de textos multimodais e o modo como os mesmos se apresentam, sejam esses digitais ou não.

Desse modo, a leitura de um livro de imagens proporciona à criança uma participação ativa na leitura, na qual a narrativa sai do poder do adulto e passa a ser direcionada pela criança. A função do professor passa a ser de mediar esse contato da criança com o livro, explorando e enriquecendo essa experiência.

Considera-se a importância do trabalho com múltiplas linguagens na Educação Infantil, no qual as colocações das crianças devem ser a centralidade do trabalho pedagógico. Para tanto, a narrativa por parte das crianças é fundamental. $\mathrm{Na}$ contação de histórias, a partir de imagens, essa narrativa pode ser ricamente explorada, pois a criança consegue estabelecer um elo entre a fantasia e as informações que traz da sua realidade.

Sendo assim, pretende-se trazer uma contribuição que possibilite uma reflexão sobre práticas pedagógicas voltadas para o letramento. Neste trabalho se apresenta a metodologia utilizada na pesquisa; os conceitos utilizados como base para 
a pesquisa e para a elaboração do trabalho e, por fim, uma breve orientação para o profissional de Educação Infantil para o trabalho com o letramento visual.

O Referencial Curricular Nacional da Educação Infantil - RCNEI e as Orientações Curriculares para a Educação Infantil - OCNEI foram pontos de partida para análise e para esclarecer tal questão e basear teoricamente a pesquisa, sendo utilizados conceitos de letramento como uso social da língua de Soares (1998); pedagogia dos multiletramentos de Rojo (2012; letramento visual, segundo Kress e Van Leeuwen (2001) que se baseia na Linguística Sistêmico Funcional de Halliday e Matthiessen (1994); e, por fim, a estrutura narrativa proposta por Labov (1972).

Esta investigação e a elaboração do produto foram realizadas no âmbito do Grupo de Estudos e Pesquisas em Lingua(gem) e Projetos Inovadores na Educação - GEPLIED, liderado pela Prof. a Dr. . . Alda Maria Coimbra Aguilar Maciel e vinculado ao Programa de Mestrado Profissional em Práticas de Educação Básica do Colégio Pedro II (MPPEB-CPII).

\section{Material e Métodos}

A pesquisa foi realizada em uma Creche Municipal da Rede Pública do Município do Rio de Janeiro, no segmento Maternal I. Teve como participantes 26 crianças e quatro professoras. Tratou-se de uma pesquisa-ação, que segundo Gil (2010) se concretiza com planejamento da ação destinado a enfrentar um problema, que foi objeto de investigação.

Selecionamos os seguintes instrumentos para coleta de dados:

$>$ questionário, com a finalidade de levantar dados sobre o conhecimento das professoras sobre o tema e se esses conhecimentos são aplicados por elas;

$>$ registros do "livrão", composto de controle de frequência e caderno, no qual as professoras registram as atividades;

$>$ registros em diário de campo das atividades realizadas pela pesquisadora.

As docentes responderam ao questionário informando os seus conhecimentos sobre o tema multiletramento e letramento visual e a frequência da utilização desses temas em sala de aula; os vinte e seis alunos participaram das atividades propostas por esta pesquisa. A pesquisadora, após a análise do embasamento teórico e dos conteúdos, aplicou o produto na turma citada.

A aplicação do questionário é relevante na medida em que é usado para conhecer a opinião das professoras sobre o tema pesquisado e se as mesmas já fazem uso dos conceitos no seu planejamento pedagógico. Esse contém perguntas que investigam o conhecimento sobre multiletramentos e quais as possíveis práticas que as docentes já utilizam ligadas ao tema.

O questionário foi fundamental para a elaboração do produto, bem como os registros e diários de campo, que nortearam na análise dos resultados das atividades.

A técnica de análise de dados foi a de conteúdo, essa se apresenta como um conjunto de técnicas de análise das comunicações, que faz uso de métodos sistemáticos e objetivos de definição do teor das mensagens.

Todos esses dados foram analisados para a elaboração do produto, para que esse fosse realmente útil e relevante para o público destinado.

\section{Resultados e Discussão}

A história da Educação Infantil segue as mudanças ocorridas na história e nas diferentes concepções de sociedade, de família e de infância. Na Idade Média, por exemplo, não existia a diferença entre adulto e criança e nem mesmo a concepção de infância. Ariès (1981) destaca que o sentimento de infância não existia nesse período, a essa não se dava um tratamento característico da sua faixa etária e as suas especificidades que a distinguisse dos adultos.

Os primeiros livros para crianças surgem no século XVII e XVIII na Europa, até então não havia literatura voltada para essa fase, pois ainda não havia a concepção de infância. A infância e a literatura infantil surgem em decorrência da ascensão da família burguesa. A criança passa a ser entendida como um ser distinto do adulto, com suas próprias especificidades e necessidades. Cademartori (1994, p.23) afirma que:

a literatura infantil se configura não só como instrumento de formação conceitual, mas também de emancipação da manipulação da sociedade. Se a dependência infantil e a ausência de um padrão inato de comportamento são questões que se interpenetram, configurando a posição da criança na relação com o adulto, a literatura surge como um meio de superação da dependência e da carência por possibilitar a reformulação de conceitos e a autonomia do pensamento.

No campo educacional, o surgimento da Educação Infantil, em especial, nas instituições públicas de ensino, é um movimento recente no Brasil. As primeiras creches surgiram com a revolução industrial na necessidade da inserção da mulher no mercado de trabalho. Nessa época, o atendimento era de cunho assistencialista e, por isso, por muito tempo, esses espaços eram considerados "depósitos" de crianças.

A Educação Infantil vem sendo transformada ao longo dos anos, acompanhando os modelos de sociedade vigente. As políticas públicas também foram fundamentais para formar o modelo de Educação Infantil que se tem hoje. Destaca-se sempre a importância de Educação Infantil de qualidade e as experiências nessas vivenciadas para a formação do sujeito.

Pensando no espaço da Educação Infantil , Zabala (1998) destaca que a capacidade de uma pessoa para se relacionar depende das experiências que vivem, e as instituições educacionais são um dos lugares prediletos. Nessa fase da vida, criam-se vínculos e relações que definem os próprios pontos de vista pessoais sobre si mesmo e sobre os demais.

Destaca-se um dos principais documentos que orientam o professor para o trabalho nessa etapa tão importante da Educação Básica, o DCNEI (2010), ressaltando o que o mesmo traz sobre a linguagem oral e escrita na Educação Infantil . 
De acordo com a DCNEI (2010, p.25) a linguagem oral e escrita deve promover experiências que:

Favoreçam a imersão das crianças nas diferentes linguagens e o progressivo domínio por elas de vários gêneros e formas de expressão: gestual, verbal, plástica, dramática e musical;

Possibilitem às crianças experiências de narrativas, de apreciação e interação com a linguagem oral e escrita, e convívio com diferentes suportes e gêneros textuais orais e escritos.

Partindo do documento acima citado, destaca-se a importância em envolver a criança em atividades que promovam experiências com as práticas sociais de leitura e escrita. A função social da leitura e da escrita (SOARES, 1998) pode ser considerada um dos fatores que difere os termos letramento e alfabetização. De acordo com a autora, alfabetizado nomeia apenas quem aprendeu a ler e escrever, não aquele que adquiriu o estado ou condição de quem se apropriou da leitura e da escrita, incorporando as práticas sociais que as demandam (SOARES, 1998).

Portanto, o conceito de letramento vai além de um método da aquisição da leitura e da escrita. O termo expressa uma maneira diversificada de considerar essas habilidades na sociedade, que vai além daqueles ensinados nas instituições de ensino.

Já a Pedagogia do Multiletramento, de acordo com Rojo (2012), não se restringe aos vários modos de estimular os eventos de letramento, mas envolve também os aspectos culturais, que estimulam a inclusão sociocultural, por meio de práticas como a que se propõe aqui.

No modelo atual de sociedade são encontrados diversos recursos semióticos que são utilizados no dia a dia. Os textos, por sua vez, estabelecem várias relações entre as multimodalidades, como som, cor, links, imagens, entre outros. Oliveira (2013, p.2) aponta que:

Nas práticas sociais pós-modernas, os cidadãos estão cada vez mais sendo expostos à leitura de textos que misturam escrita, layout, imagens, som e objetos 3D. Entretanto, apesar do uso intensivo da imagem fora do ambiente escolar, ainda é insuficiente a sistematização do uso dessas imagens para fins pedagógicos. Nesse sentido, nas últimas décadas, pesquisas realizadas em diferentes correntes da linguística têm dedicado parte de seus estudos ao que se refere às 'práticas do (multi) letramento' como instrumento do exercício da cidadania.

Assim, cada cultura desempenha práticas de letramento de maneiras diversas, seja na família, na instituição religiosa, nos espaços informais, e todas devem ser valorizadas. Com a globalização, a cultura dita superior prevalece em todos esses espaços, sobretudo, no espaço escolar.

\subsection{Principais concepções para a elaboração do produto educacional}

Para o trabalho com a multimodalidade e com o letramento visual se estão utilizando os conceitos da Gramática do Design Visual (GDV), propostos por Kress e Van Leeuwen (2006), baseados no aporte teórico da Linguística Sistêmico Funcional de Halliday (1994). Tais teorias ajudaram na elaboração do Caderno Pedagógico aqui apresentado.

As metafunções (ideacional, interpessoal e textual), sugeridas por Halliday (2004), são aplicadas pela GDV como suporte para a análise das imagens. A tabela a seguir demonstra como cada metafunção é utilizada para interpretar a imagem.

Quadro 1 - As metafunções na interpretação das imagens

\begin{tabular}{|c|l|}
\hline Metafunção & Função na análise da imagem. \\
\hline Ideacional & $\begin{array}{l}\text { Representa a função que a imagem tem de } \\
\text { reproduzir o mundo que nos cerca. }\end{array}$ \\
\hline Interpessoal & $\begin{array}{l}\text { Estabelece o modo como a imagem interage } \\
\text { com o leitor, podendo aproximar ou afastar o } \\
\text { mesmo. }\end{array}$ \\
\hline Textual & $\begin{array}{l}\text { Estabelece a função da imagem de se organizar } \\
\text { de forma coerente com o seu contexto de } \\
\text { produção. }\end{array}$ \\
\hline
\end{tabular}

Fonte: Dados da pesquisa.

As metafunções acima apresentadas auxiliaram na avaliação dos textos imagéticos para a elaboração do caderno pedagógico, sobretudo, a obra selecionada "O jornal", que traz diversas modalidades de imagens que possibilitam ser ricamente exploradas.

O conceito de multimodalidade é importante para analisar a relação entre texto escrito e imagens. Esse conceito permite a interpretação dos sentidos sociais constituídos por esses textos e seu significado nas práticas de letramento.

Vinculada com a interpretação de imagens, a narrativa também ajudará a compor o produto, já que se destaca sempre a importância de ouvir a criança. Nesse sentido, o aluno irá criar as suas narrativas a partir na interpretação de imagens, que por sua vez, será estimulada e mediada pelo professor de acordo com os seus conhecimentos sobre as categorias da GDV.

Quadro 2 - Etapas de uma narrativa

\begin{tabular}{|c|l|}
\hline Resumo & $\begin{array}{l}\text { Apresenta, de forma breve, o tema da história } \\
\text { e tem como função resumir a narrativa. Por ser } \\
\text { opcional, pode ou não estar presente. Por se } \\
\text { apresentar na "extremidade" da narrativa, tem } \\
\text { função interativa; isto é, pode ser um pedido de } \\
\text { turno para falar ou a base para a negociação da } \\
\text { apresentação da narrativa. }\end{array}$ \\
\hline Orientação & Situa o leitor ao lugar, tempo e pessoa. \\
\hline $\begin{array}{c}\text { Complicação } \\
\text { da ação }\end{array}$ & $\begin{array}{l}\text { Narra a ordem dos acontecimentos e compõe o } \\
\text { corpo da narrativa. }\end{array}$ \\
\hline Avaliação & $\begin{array}{l}\text { Demonstra a ação do narrador em relação à } \\
\text { narrativa. Pode aparecer ao longo da narrativa } \\
\text { e pode ser revelada por diversas estruturas } \\
\text { linguísticas, como, por exemplo, o tom de voz. }\end{array}$ \\
\hline Resolução & $\begin{array}{l}\text { Revela o que ocorreu, como foi solucionada a } \\
\text { complicação. }\end{array}$ \\
\hline Coda & $\begin{array}{l}\text { Constitui o mecanismo que traz a narrativa de } \\
\text { volta ao momento presente. Sinaliza, também, o } \\
\text { final da narrativa. }\end{array}$ \\
\hline
\end{tabular}




\begin{tabular}{|c|l|}
\hline \multirow{2}{*}{ Resumo } & $\begin{array}{l}\text { Esta é uma breve apresentação do tema da } \\
\text { história que tem como função resumir a } \\
\text { narrativa. Por ser opcional, pode ou não estar } \\
\text { presente. Por se apresentar na "extremidade" da } \\
\text { narrativa, ele tem uma função interativa; isto é, } \\
\text { pode ser um pedido de turno para falar ou a base } \\
\text { para a negociação da apresentação da narrativa. }\end{array}$ \\
\hline Orientação & Situa o leitor ao lugar, tempo, pessoa. \\
\hline $\begin{array}{c}\text { Complicação } \\
\text { da ação }\end{array}$ & $\begin{array}{l}\text { É relativo ao corpo da narrativa e narra a ordem } \\
\text { dos acontecimentos. }\end{array}$ \\
\hline Avaliação & $\begin{array}{l}\text { Demonstra a ação do narrador em relação à } \\
\text { narrativa. Pode aparecer ao longo da narrativa } \\
\text { e pode ser revelada por diversas estruturas } \\
\text { lingüísticas, como, por exemplo, o tom de voz. }\end{array}$ \\
\hline Resolução & $\begin{array}{l}\text { O que ocorreu, como foi solucionada a } \\
\text { complicação. }\end{array}$ \\
\hline Coda & $\begin{array}{l}\text { É o mecanismo que faz com que a narrativa } \\
\text { volte ao momento presente. Sinaliza, também, } \\
\text { o final da narrativa. }\end{array}$ \\
\hline
\end{tabular}

Fonte: Dados da pesquisa.

Os estudos sobre a GDV, a LSF e a estrutura narrativa de Labov, vêm para colaborar com as demais teorias aqui expostas, tendo em vista que as mesmas tratam o texto em seu contexto social e cultural.

\subsection{Caderno pedagógico como uma proposta de ensino}

A seguir, demonstra-se brevemente a proposta partindo das teorias aqui apresentadas, da colaboração das professoras utilizando os questionários por elas respondidos e da análise do planejamento realizado pelas mesmas.

Utiliza-se a obra "O jornal” para a demonstração da proposta. "O jornal" é um livro de imagens lançado pela editora Brinque-book, cuja autora e ilustradora é Patrícia Auerbach ${ }^{1}$. O livro tem uma vasta ilustração e faz parte do acervo do $P N B E^{2}$ na escola: literatura fora da caixa, do ano de 2014, desenvolvido pelo Ministério da Educação (MEC), o que motivou a escolha. Tal publicação é distribuída para todas as instituições públicas de Educação Infantil, inclusive a instituição na qual esta pesquisa foi realizada.

Soares e Paiva (2014, p.13), no guia que acompanha o acervo supracitado, orientam sobre a importância da leitura literária na Educação Infantil:

Espera-se que, nesse segmento da escolaridade, as crianças tenham contato permanente com esses bens culturais que são os livros de literatura, para que se familiarizem com eles de modo a interagir com a linguagem literária - nos textos e nas ilustrações -, preparando-se para compreender também esses usos sociais da escrita.

A sequência de atividades proposta a seguir foi baseada na estrutura narrativa desenvolvida por Labov (1972) e a análise de imagens de acordo com as categorias da Gramática do Design Visual desenvolvida por Kress e Van Leeuwen.

Por meio dessas atividades se busca colocar em prática a articulação de todas as teorias aqui demonstradas, pois se acredita que uma teoria que não se constitui em prática perde o seu sentido.

Diante disso, segue uma breve demonstração das atividades que estão sendo elaboradas para o caderno pedagógico:

Atividade 1: Exploração do livro "O jornal"

Etapa I: Apresentando a história; Etapa II: Reconhecendo os personagens; Etapa III: Explorando os acontecimentos; Etapa IV: Dando vida à narrativa; Etapa V: Estimulando a percepção; Etapa VI: Encerrando

Atividade 2: Registro de falas e ideias da classe

Atividade 3: Desenho sobre o livro "O jornal"

Atividade 4: Confecção de um livro a partir das narrativas das crianças

Atividade 5: Culminância

Atividade 1: Exploração do livro "O jornal"

Objetivo: desenvolver o letramento visual por meio da exploração da narrativa do livro "O jornal".

Duração: a contação de história será dividida em dois dias, 20 minutos para cada dia.

Nesta atividade, faz-se uso das etapas da estrutura narrativa de Labov para a contação de história (Quadro 3).

Quadro 3 - Sequência das etapas da narrativa

\begin{tabular}{|l|l|}
\hline Estrutura Narrativa & Sequências Das Etapas \\
\hline Resumo & I- Apresentando a história \\
\hline Orientação & II- Reconhecendo os personagens \\
\hline Complicação da ação & III- Explorando os acontecimentos \\
\hline Avaliação & IV- Dando vida à narrativa \\
\hline Resolução & V- Estimulando a percepção \\
\hline Coda & VI- Encerrando \\
\hline
\end{tabular}

Fonte: Dados da pesquisa.

Desenvolvimento das etapas da contação de história:

$>$ Etapa I: Apresentando a história

$>$ Etapa II: Reconhecendo os personagens

$>$ Etapa III: Explorando os acontecimentos

Nessas etapas se utiliza a GDV para a exploração junto às crianças, por meio das estratégias da professora. As categorias da GDV foram empregadas para identificar as funções das imagens em determinado contexto. Assim sendo, nessa fase, é fundamental que a professora conduza a contação de histórias a favor da exploração da narrativa e da criatividade da criança, que possui suas próprias considerações.

$>$ Etapa IV: Dando vida à narrativa

$>$ Etapa V: Estimulando a percepção

$>$ Etapa VI: Encerrando

Atividade 2: Registro de falas e ideias da classe.

Objetivos: promover o letramento por meio do registro; valorizar a participação das crianças; duração: 20 min para cada um dos dois dias de contação de história.

Atividade 3: Desenho sobre o livro "O jornal"

Objetivos: estimular a produção artística; explorar a criatividade; associar o desenho a história narrada; duração: 
$20 \mathrm{~min}$.

Atividade 4: Confecção de um livro a partir das narrativas das crianças.

Objetivo: estimular a criação das crianças; explorar novas narrativas; criar um novo material para o acervo; duração: 20 $\min$.

\section{Atividade 5: Culminância}

Objetivos: envolver a família e a comunidade escolar na produção das crianças; explorar a oralidade; estimular as práticas de letramento; expor a função da imagem; duração: 40 min. para visitação e apresentação.

Considera-se que na Educação Infantil, o contato com a leitura e a escrita deve ser realizado com o objetivo de proporcionar às crianças diferentes experiências, que não se limitem ao contato com as letras de forma mecânica e descontextualizada. Acredita-se, sobretudo, que esta não é a etapa na qual a criança deverá ser alfabetizada.

Propõe-se que um ambiente letrado e os eventos de letramento devem se constituir como ambiente e eventos interacionais, que envolvam todos os atores: tanto o adulto, quanto a criança, com a leitura e a escrita, em uma relação de troca e não de hierarquia.

Propõe-se, também, uma reflexão com base nas teorias apresentadas, que se complementam quando buscam demonstrar a função social da escrita (SOARES, 1998) e no caso da GDV, a função da imagem no texto e como texto.

\section{Conclusão}

Para promover o letramento visual, utiliza-se a contação de histórias por meio da obra "O jornal”, porque ler histórias para as crianças é algo amplamente utilizado pelas professoras na Educação Infantil e fundamentado em uma teoria o produto poderá ser mais útil para as professoras e para as crianças. Porém, na atividade aqui planejada e executada, a criança também possuiu o papel de narrador, e foi possível concluir que a imagem foi o principal elemento para estimular a imaginação e a criatividade desses pequenos contadores de história.

Ouvir a criança é mais do que explorar a oralidade, é saber identificar seus anseios, é ter a oportunidade de refletir sobre a própria prática e ter a percepção sobre o significado dessas para as crianças. É uma experiência de troca de aprendizado ou de aprendizado mútuo.

Espera-se que por meio dessa pesquisa aqui apresentada e com o produto educacional - o caderno pedagógico - as crianças possam ter práticas significativas em torno da sua cultura com situações desafiadoras, possibilitando que elas façam análises críticas, de forma a ampliar seus conhecimentos, inclusive de mundo.

A Educação Infantil é a etapa privilegiada para o trabalho reflexivo com as crianças. Os professores podem apresentar inúmeras possibilidades, nas quais a aprendizagem ocorre por meio da troca e do reconhecimento da criança como sujeito da sua própria ação. Assim, estudos como o aqui apresentado possam impulsionar esses profissionais para tais práticas.

\section{Referências}

ARIÈS, P. História social da criança e da família. Rio de Janeiro: Afiliada, 1981.

AUERBACH, P. O jornal. São Paulo: Brinque-book, 2012.

BRASIL, Ministério da Educação. Secretaria de Educação Básica. Diretrizes Curriculares Nacionais para a Educação Infantil. Brasília: MEC, 2010.

BRASIL, Ministério da Educação e do Desporto. Referencial Curricular Nacional para a Educação Infantil. Brasília, MEC, 1998.

CADEMARTORI, L. O que é literatura infantil? São Paulo: Brasiliense, 1994.

GALVÃO, C. Narrativas em Educação. Ciênc. Educ., v.11, n.2, p.327-345, 2005 .

GIL, A.C. Como elaborar projetos de pesquisa. São Paulo: Atlas, 2010.

HALLIDAY, M.A.K. An introduction to functional grammar. London: Arnold, 1994.

HALLIDAY, M.A.K.; MATTHIESSEN, C.M.I.M. An introduction to functional grammar. London: Arnold, 2004.

KRESS, G.; VAN LEEUWEN, T. Multimodal discourse: the modes and media of contemporary communication. London: Oxford University Press, 2001.

KRESS, G. Reading images: the grammar of graphic design. London: Routledge, 2006.

LABOV, W. The transformation of experience in narrative syntax. Language in the inner city. Philadelphia: University of Philadelphia Press, 1972.

BRASIL. Ministério da Educação. PNBE na escola. Literatura fora da caixa. Brasília: MEC, 2014.

OLIVEIRA, D. Gêneros multimodais e multiletramentos: novas práticas de leitura em sala de aula. Itabaiana: UFS, 2013.

ROJO, R. Multiletramentos na escola. São Paulo: Parábola, 2012.

SANTOS, Z. A construção de uma leitura multimodal em língua estrangeira. Rev. Educ. Destaque, v.1, n. 2, p.75-86, 2008.

SOARES, M.B. Letramento: um tema em três gêneros. Belo Horizonte: Autêntica, 1998.

ZABALA, A.A. Prática educativa: como ensinar. Porto Alegre: ArtMed, 1998. 